\title{
Predictors of local support for a seawater desalination plant in a small coastal community
}

\author{
Nadine Heck ${ }^{a, *}$, Adina Paytann ${ }^{a, b}$, Donald C. Potts ${ }^{c}$, Brent Haddad ${ }^{d}$ \\ a Institute of Marine Sciences, University of California, Santa Cruz, 1156 High Street, \\ Santa Cruz CA 95064, USA \\ b Department of Earth and Planetary Sciences, University of California, Santa Cruz, 1156 \\ High Street, Santa Cruz, CA 95064, USA \\ c Department of Ecology and Evolutionary Biology, University of California, Santa Cruz, \\ 1156 High St., Santa Cruz, CA 95064, USA \\ d Environmental Studies, University of California, Santa Cruz, 1156 High St., Santa Cruz, \\ CA 95064, USA \\ * Corresponding author. \\ E-mail addresses: nheck@ucsc.edu (N. Heck), apaytan@ucsc.edu (A.Paytan), \\ potts@ucsc.edu (D.C.Potts), bhaddad@ucsc.edu (B. Haddad).
}

\section{Abstract}

Seawater desalination is increasingly being pursued to address freshwater shortages. In California, multiple coastal seawater desalination facilities have been proposed to diversify water portfolios and to increase reliability of water supply. This paper explores local residents support for a newly constructed desalination plant in Carlsbad, a small coastal community in Southern California. The plant is the first high-capacity desalination facility in California and started operation in December 2015. We found strong support for the desalination plant as $71.9 \%$ of residents reported support for the plant. Only $15.5 \%$ of respondents were undecided indicating that residents had a clear opinion on the plant. Perceptions about local water resources were significant predictors of support. Attitudes may change over time if the state of water resources and perceptions thereof change. Expected outcomes of the plant also predicted support. An increase in available drinking water was a positive predictor, while environmental and social impacts were negative predictors. Economic impacts in terms of an increase in the price of water did not influence local support. Ethnicity and age were the only socio-demographic variables that had an effect on support suggesting that the socio demographic profile of a community may not be a good predictor of community support or rejection of this water supply technology.

This is the accepted manuscript of a paper published Environmental Science \& Policy. The final version may be accessed at https://doi.org/10.1016/j.envsci.2016.08.009. 


\section{Introduction}

Freshwater accounts for only $2.5 \%$ of the total volume of water on earth (Oki and Kanae, 2006; World Water Assessment Programme, 2009). Many regions worldwide are experiencing freshwater shortage due to increasing water consumption and environmental changes that are reducing the reliability of traditional water resources such as surface and groundwater sources (Bourne, 2008; Dolnicar and Schäfer, 2009; Seller, 2008). In response, water agencies have started to adopt measure to reduce demand for water (e.g., water conservation measures) (Martin, 2015) and to increase water supply by pursuing new technologies including seawater desalination. Seawater desalination is particularly valued for the production of high quality drinking water, for being independent of climate and for providing a reliable source of water during droughts. The sector is growing and more than 17,000 desalination plants were in operation worldwide in 2013 with a global desalination capacity of more than 80 million cubic meters per day (International Desalination Association, 2014).

In the US, seawater desalination is an emerging ocean sector with potential for growth in the future. Freshwater supplies in coastal areas relying on imported and groundwater sources have become increasingly unreliable with changing weather patterns, recurring droughts, and altwater intrusion into aquifers due to low groundwater levels that could be aggravated by rising sea levels (Bourne, 2008; Heberger et al., 2009; Mirchi et al., 2013; Sellers, 2008). Water authorities are subsequently seeking to diversify coastal water portfolios with seawater desalination. The technology is expected to reduce dependence on imported water and underground aquifers in coastal areas, and to help satisfy increasing demand for drinking water due to growth in coastal population and industries (California Coastal Commission, 2004; Monterey Bay National Marine Sanctuary and National Marine Fisheries Service, 2010; Peel and Choy, 2014; State of California Public Utilities Commission, 2015).

Desalination development, however, remains controversial due to potential environmental economic, and societal impacts (Cooley et al., 2013; Fuentes-Bargues, 2014; Liu et al., 2013). Seawater desalination is a relatively expensive technology that increases the water price for consumers (Cooley and Heberger, 2013; Côté et al., 2005; Dawoud, 2005; Hinkebein and Price, 2005; Schiffler, 2004). The development of desalination plants can also reduce public access to coastal areas, disrupt coastal recreation activities, and alter aesthetics of the coastal landscape (California Department of Water Resources, 2003; Liu et al., 2013; Sellers, 2008).

Environmental impacts of desalination plants compare to some extent to impacts of other coastal developments (e.g. land use change) (Lattemann and Höpner, 2008). Effects more specific to desalination are consequences of the intake of large quantities of water and brine discharge, including mortality of larvae and other organisms due to impingement and entrainment during seawater intake. Brine discharge can lead to degradation of marine habitats, impacts on marine life on the ocean floor, coastal eutrophication, and changes in seawater quality, in addition to changes in coastal hydrology during construction (e.g., Elimelech and Phillip, 2011; Lattemann and Höpner, 2008; Roberts et al., 2010; Sanchez-Lizaso et al., 2008). Indirect impacts such as ocean acidification and sea level rise may also result from 
increasing greenhouse gas emissions from the relatively high energy consumption of operating seawater desalination plants (Cooley and Heberger, 2013; Miller et al., 2015). Specifically, as nearshore areas can be important habitat and spawning areas, both intake and brine discharge add further stress to marine environments already affected by a variety of anthropogenic activities (Halpern et al., 2008).

Another consideration for seawater desalination plants are their effects on marine protected areas that are increasingly being established all around the world. One example in the US is the newly created Marine Protected Area (MPA) network along the coast of California. This network is the first of its kind in the US and consists of 124 MPAs intended to safeguard the productivity and diversity of marine life and habitats in coastal California for current and future generations (Natural Resources Defense Council, 2014). Seawater intake and brine discharge from desalination plants built in close proximity to MPAs could have impacts on protected values within individual MPA sites. Reduction of larval connectivity between MPAs, due to entrainment and impingement in the intake pipes of desalination facilities, might further compromise the effectiveness of the broader MPA network (Natural Resources Defense Council, 2014). While a number of studies have suggested that changes in marine ecosystems resulting from desalination activities might also lead to impacts on recreational and commercial marine users (Liu et al., 2013; Monterey Bay National Marine Sanctuary and National Marine Fisheries Service, 2010), these impacts have not been systematically studied to date.

\subsection{Public perception of seawater desalination}

Development of seawater desalination plants in the US has been slow so far. Changes in regulations (e.g., State Water Resources Control Board, 2014) and opposition of environmental groups and coastal residents have slowed down the development of proposed new plants (e.g., Desal Alternatives, 2013; Pasko, 2013). Even though community acceptance can be critical for the implementation of desalination plants, little is known about community reactions to desalination plants and the variables that influence attitudes towards this water supply option.

Previous studies on attitudes towards water schemes, such as desalination, fall into three categories. The first include studies on general attitudes towards a water supply option by asking the public wide ranging questions that are not attached to a specific project. The second are studies focusing on public opinions on actual forthcoming water projects, and the third researches attitudes in locations where a new water supply scheme has already been put in place (Friedler et al., 2006).

Compared to water conservation (e.g. Tortajada and Joshi, 2013) and alternative water schemes such as water recycling (e.g., Ching, 2016; Hartley, 2006; Bridgeman, 2004), literature on attitudes towards seawater desalination is still very limited. Most previous studies on desalination fall into the first category and examine general attitudes towards seawater desalination as a water supply option (King et al., 2012) and acceptance of using desalinated water (e.g., Dolnicar et al., 2011, 2010; Dolnicar and Schäfer, 2009; Theodori et al., 2009). These studies have been informed to a great extent by theoretical approaches in social psychology and psychological risk perception literature (e.g., Ajzen and Fishbein, 1988; Pidgeon and 
Beattie, 1998). The main concerns with using desalinated water were perceived environmental impacts, costs, quality of desalinated water and associated health concerns. Acceptance was also influenced by socio-economic variables including education, age, and gender. Acceptors of desalinated water were older, male, educated, and had previously used desalinated water. Psychological factors that shaped acceptance of using desalinated water included positive attitude towards conservation and the environment, and social norms (Dolnicar et al., 2011; Dolnicar and Schäfer, 2009). Environmental concerns also lowered public preference for desalination as an alternative water supply in Spain (Domènech et al., 2013) and Australia (King et al., 2012).

Studies on actual or forthcoming projects are even more limited. One study by Gibson et al. (2015) explored public acceptance of expanding desalination in Perth, Australia. The authors compared the influence of attitudinal and socio-demographic factors on public voting behavior for or against additional desalination plants in Perth in 2007 and 2012 and found support for the expansion of desalination in both years (74.5\% in 2007 and $73.4 \%$ in 2012) but the drivers of acceptance changed over time.

Our work builds on existing studies and explores public support for a newly established desalination plant in a small coastal community in Southern California. In contrast to studies on general acceptance of seawater desalination (King et al., 2012), of using desalinated water (e.g. Dolnicar and Schäfer, 2009), or support for future projects (Gibson et al., 2015), we investigate local support for a local desalination project that has recently been completed. Understanding attitudes towards a particular project is crucial for the siting of new plants. Even if the wider consumer constituency is in favor of desalination, individual communities may oppose a project in their area, which can lead to significant delays or even abandonment of water supply projects (Hurlimann and Dolnicar, 2010; Mainali et al., 2011; Pierce, 2013). Assessing local residents' views on plants within their community is critical for understanding why communities support or oppose these projects.

The aims of the paper are to (1) assess local perceptions of water resources and outcomes of the newly built desalination facility; (2) evaluate local support for the plant; (3) identify variables that shape and predict local support. We explore whether the sociodemographic profile of a community affects local support as previous studies reported significant relationships between sociodemographic variables and attitudes towards proposed desalination plants (Gibson et al., 2015) and acceptance of using desalinated water (Dolnicar and Schäfer, 2009). We also investigate whether frequent use of local marine areas affects support since a number of studies have suggested that impacts on marine ecosystems from desalination might lead to impacts on recreational and commercial marine users and create conflicts with existing activities (Liu et al., 2013; Monterey Bay National Marine Sanctuary and National Marine Fisheries Service, 2010).

Our study further investigates whether the design of the plant and the environmental context shapes local acceptance. Most common critiques of seawater desalination include environment impacts due to open-ocean intake, brine discharge, $\mathrm{CO} 2$ emission, high costs, and loss of 
coastal access and scenery. While previous studies report that general environmental concerns and economic costs affect support for desalination (King et al. 2012; Domènech et al., 2013; Gibson et al., 2015), little is known about the influence of project specific outcomes on local support.

Another important consideration for public support of water supply schemes is the notion of threat perceptions (Marks, 2004). The public is more likely to support new water supply schemes if there is a severe water crisis that threatens local water supply (Mankad and Tapsuwan, 2011). On the other hand, threats to personal health, such as the concerns about quality of desalinated water have been found to reduce acceptance (Dolnicar and Schäfer, 2009). Our study explores whether perceived threats based on concerns about the local water supply and perceptions about the quality of the local marine environment that is the water sources for the new desalination plant has any effect on local support.

In addition, we draw from the literature on the acceptance of other coastal resource projects (e.g. tidal energy, off-shore energy) and investigate the influence of place attachment. Whereas sense of place is concerned with factors creating bonds to a place (e.g. Stedman, 2002), place attachment refers to the strength of bonds between humans and locations (Wynveen et al., 2011). While place attachment can be assessed in many ways, the two main dimensions with strong foundations in the academic literature are place identity and place dependence (Manning, 2011; Williams and Vaske, 2003). Place identity, emotional ties to a place, usually develops over time and refers to the symbolic meanings of an area. Place dependence is the functionality associated with an area and is represented by its tangible physical characteristics and attributes (Williams and Vaske, 2003). As coastal residents and marine users often place emotional and functional importance to marine areas (e.g., Gee and Burkhard, 2010; Gray et al., 2010; Ressurreição et al., 2012), place attachment can shape their attitudes towards the use or protection of these areas. Previous studies have reported that place attachment explained attitudes towards the use of coastal and marine resources even more than socio-demographic variables (Devine-Wright, 2011; Vorkinn and Riese, 2001).

Residents further may oppose natural resource projects in their close proximity even though they would otherwise support them. We explore this issue in the context of desalination based on the NIMBY framework to identify whether proximity of residence to a new plant has an effect on support. The NIMBY framework has been widely used to explore if proximity to a new development influences local residents' attitudes. NIMBY has been explored since the early 1980s for multiple natural resource projects (e.g., energy plants, natural gas extraction, wind farms, off-shore oil drilling platforms) (Kahn, 2000; Michaud et al., 2008; Wolsink, 1994, 2000; Jacquet, 2012; Johansson and Laike, 2007; Swofford and Slattery, 2010). For desalination, NIMBY could provide insights to the question if coastal residents close to the new facility oppose the plant compared to those living further away. In this instance, the public may support desalination as a water supply option in general but not the construction of such a facility in their immediate vicinity. 


\section{Methods}

\subsection{Case study area}

Carlsbad, a seaside resort of 112,299 residents in Southern California, is part of the San Diego County Water authority district (Fig. 1).

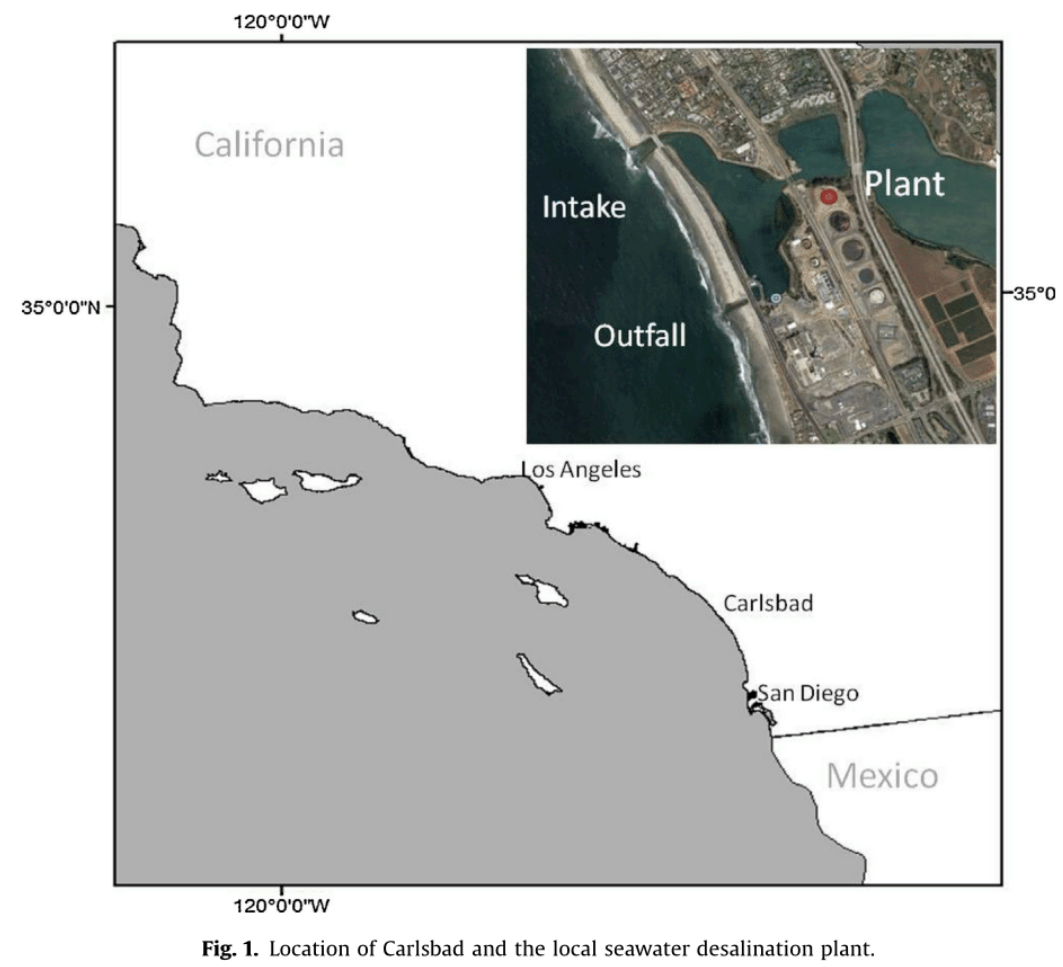

Fig. 1. Location of Carlsbad and the local seawater desalination plant.

Residents in Carlsbad are older (median age 41.7 years), affluent (median income $\$ 87,416$ ), educated with a bachelor's degree or higher (51.9\%), and predominantly white $(82.8 \%)$ (California Demographics, 2014; United States Census Bureau, 2014). The offshore marine area adjacent to the plant site is part of the geographic zone known as the Southern California Bight (SCB), which encompasses about 56,979 km2 (22,000 square miles) from Point Conception in the north to Cabo Colnett in Baja California in the South. The coast adjacent to the plant consists of 50-70 $\mathrm{m}$ wide beaches backed in places by 12-24 high marine terrace bluffs.

Important habitats in the area include intertidal sand habitats, subtidal soft bottom habitats, and subtidal hard bottom habitats. Abundant benthic organisms in the soft bottom habitats include clams, snails, polychaete worms, arthropods (crabs and shrimps), fishes and offshore kelp beds, while the nearshore water column contains pelagic fishes, phytoplankton and zooplankton.

The San Diego water district receives about $64 \%$ of its drinking water from the Colorado River, approximately $20 \%$ from the state water project in Northern California, and only $16 \%$ from local 
sources (Anderson, 2015). The supply from imported resources has become increasingly unreliable due to changing weather patterns, reduced snowpack in the Sierra Nevada mountains, less precipitation, and multi-year drought conditions (Mirchi et al., 2013). To diversify its water portfolio, the San Diego Water Authority entered a 30-year water purchase agreement with a private investor, Poseidon Resources for 56,000 acre-feet of desalinated water per year starting at the time of operation of the new facility (San Diego County Water Authority, 2014). Water provided by the Carlsbad desalination plant will increase local supply to about $26 \%$ and increase water prices for homeowners by about $\$ 5$ per month (San Diego County Water Authority, 2012). The plant has been in development since 1998. After multiple delays in the permitting process, the plant started operation in December 2015.

The newly constructed desalination plant is located in a more industrial area of the coast on the southern end of a 162 ha (400 acre) lagoon, the Agua Hedionda Lagoon, part of which is used for mussel and oyster aquaculture. Both, the lagoon and offshore areas are popular for fishing, paddle boarding, kayaking, beach walking, wildlife viewing (including nearby whale watching), recreational boating, and surfing.

At full capacity, the seawater desalination plant pumps about 300 million gallons per day (mgd) of seawater via an open ocean intake technology (California Water Boards, 2014; Poseidon Water, 2008). The desalination process uses $100 \mathrm{mgd}$ of seawater to produce $50 \mathrm{mgd}$ of high quality drinking water via reverse osmosis, and $50 \mathrm{mgd}$ of salty brine with a concentration of about $67,000 \mathrm{ppm}$ (twice the concentration of incoming seawater). Prior to discharge, the brine will be diluted with the additional $200 \mathrm{mgd}$ of pumped seawater. Chemicals used in cleaning processes are discharged to the sanitary sewer system for treatment and disposal (Poseidon Water, 2016).

The plant is co-located with the Encina power plant that has been in place since 1954 . While the desalination plant gets its energy from the power supply network in San Diego County and not the Encina power plant directly, it shares the existing seawater intake and outfall infrastructure. The co-location eliminated the need to construct new intake and outfall structures. As the desalination plant is expected to outlast the Encina power plant, the plant operator has acquired the right to use the intake and outfall structures for up to 60 years to ensure continued full operation (Poseidon Water, 2016).

\subsection{Mail survey among local residents}

We conducted a questionnaire-based survey between March and May 2015 to identify factors that shape coastal residents' attitudes towards the seawater desalination plant. At the time of the study, the desalination plant had finished construction but had not yet started operation. Questionnaires were administered by mail to a sample of 1500 residents in Carlsbad, California. The sample was randomly selected from postal records. Questionnaires were administered using three mailings following Dillman et al. (2014). The first and third mailings consisted of a cover letter, a booklet style questionnaire, and a prepaid return envelope. The second mailing consisted of a postcard reminder to residents who had not responded to the first mailing. The 
third mailing was sent only to addresses that had either not responded to the survey or were returned as undeliverable in the first or second mailings (Vaske, 2008). The total sample size was 330 with and response rate of $25 \%$ after accounting for undeliverable mail $(n=159)$. This response rate is consistent with similar mail surveys asking the public about natural resource issues (Connelly et al., 2003; Perry et al., 2014; Vaske, 2008).

\subsection{Variables}

Attitude towards the plant (dependent variable): We assessed attitudes towards the local seawater desalination plant on a 5 point scale from $1=$ strongly oppose to $5=$ strongly support. Answers were coded into $1=$ support/strongly support and $0=$ otherwise for correlation and binary regression analysis.

Socio-demographic variables: We collected information on age, gender, education, race, environmental NGO membership (Table 1), and participation in five marine activities in Carlsbad (Table 2).

Perceptions about water resources: Perceptions about the state of the local marine environment that is the source for drinking water production by the desalination plant was measured on a 5 -point scale from $1=$ very poor to $5=$ excellent. Concern about the local water supply was assessed on a 5 -point scale from $1=$ not at all concerned to $5=$ extremely concerned.

Perceptions about plant outcomes: We collected information on expected outcomes for nine items on a 3 -point scale from $0=$ no change to $2=$ very positive/very negative impact.

Place attachment: We measured place attachment based on six items similar to those used by Perry et al. (2014). We included three items on place identity (emotional ties to a place related to its symbolic meanings of an area) and three items on place dependence (functionality associated with an area represented by its tangible physical characteristic and attributes) (Williams and Vaske, 2003) (Table 2).

Proximity to plant: We geocoded residential address information of respondents and measured the distance of each address to the desalination facility using ArcGIS 10.2. All residents surveyed lived within a $15 \mathrm{~km}$ radius of the plant (Fig. 2).

\subsection{Data analysis}

Data were analyzed using SPSS 23 . We used a binary regression model to identify variables that predict support. Cases with missing values were deleted using listwise deletion. While all variables had between 304 and 331 responses, list wise deletion resulted in 290 valid cases for the regression model. Support was coded as $1=$ support/strongly support and $0=$ otherwise. Plant outcomes were coded on a 3-point scale from $0=$ no negative/recreation may be more affected by concerns about ocean water quality due to brine discharge and disruption of access to coastal areas. 


\section{Table 1}

Socio-demographic profile and frequency of ocean use.

\begin{tabular}{llll}
\hline Variable & Coding & \% Respondents & Mean value \\
\hline Gender & Male (1) & 55.5 & \\
& Female (0) & 44.5 & 56.9 \\
Age & Continuous & & \\
Education & University degree (1) & 72.9 & \\
& Otherwise (0) & 27.3 & \\
Member NGO & Yes (1) & 12.7 & \\
& No (0) & 87.3 & \\
Race & White (1) & 87.2 & \\
& Other (0) & 12.3 & \\
\hline
\end{tabular}

Table 2

Description and reliability analysis of ocean use and place attachment variables.

\begin{tabular}{|c|c|c|c|}
\hline Variable & Mean & SD & Cronbach's Alpha \\
\hline Fishing $^{\mathrm{a}}$ & 2.44 & 0.982 & \\
\hline Recreation $^{a}$ & 2.91 & 0.82 & 0.768 \\
\hline Surfing/swimming & 1.73 & 1.25 & \\
\hline Boating & 2.83 & 0.97 & \\
\hline Wildlife viewing & 1.91 & 1.12 & \\
\hline Beach walks & 3.18 & 0.93 & \\
\hline Place attachment ${ }^{\mathrm{b}}$ & 4.13 & 0.84 & 0.911 \\
\hline These areas mean a lot to me & 4.51 & 0.83 & \\
\hline I am very attached to these marine areas & 4.25 & 0.90 & \\
\hline These areas are very special to me & 4.29 & 0.87 & \\
\hline I wouldn't substitute any other area for doing the type of things I do here & 3.99 & 1.13 & \\
\hline These areas are the best place for doing what I like to do & 4.00 & 1.07 & \\
\hline For the things I enjoy most, no other place can compare & 3.86 & 1.17 & \\
\hline
\end{tabular}

${ }^{\text {a }}$ Measured on 5 -point scale $1=$ Never to $5=$ Almost every day.

b Measured on 5 -point scale of $1=$ Strongly Disagree to $5=$ Strongly Agree. 
Table 3

Reliability analysis of positive and negative outcome variables.

\begin{tabular}{lll}
\hline Variable & Cronbach's Alpha if item deleted & Cronbach's Alpha \\
\hline Positive outcomes & & 0.340 \\
Drinking water & 0.149 & \\
Coastal water level & 0.538 & \\
Saltwater intrusion & 0.254 & 0.805 \\
Negative outcomes & & \\
CO $_{2}$ emission & 0.772 & \\
Marine ecosystem & 0.733 & \\
Marine activities & 0.754 & \\
Water price & 0.832 & \\
Coastal access & 0.770 & \\
Coastal scenery & 0.773 & \\
\hline
\end{tabular}

\section{Results}

\subsection{Perception of water resources}

We first assessed perceptions of water resources. 52.5\% of residents in Carlsbad were extremely concerned about water supply in their community (Fig. 3). $67.8 \%$ thought that the local marine environment that is the water source for desalination is in good to excellent condition (Fig. 4). 


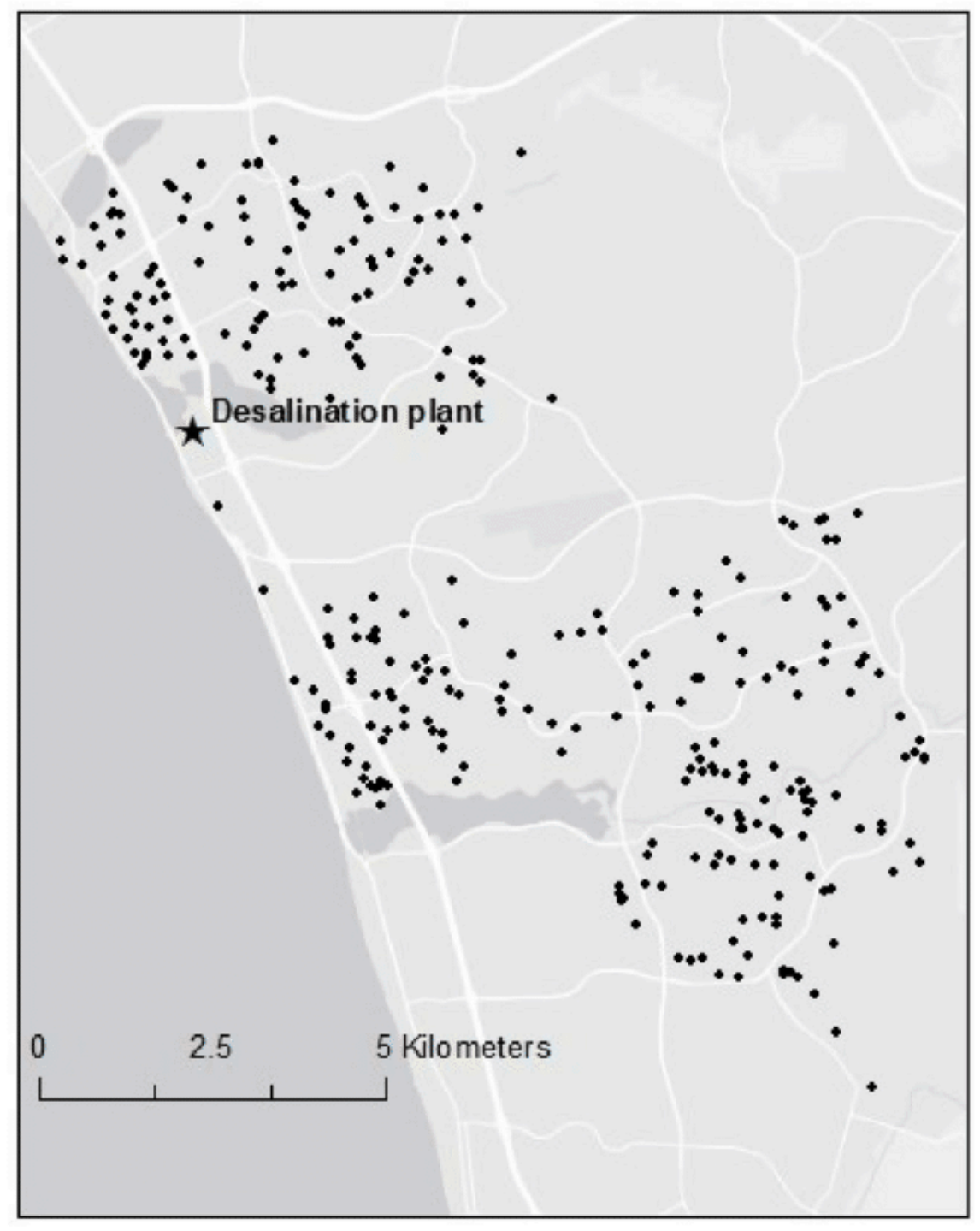

Fig. 2. Proximity of respondents to desalination facility. 


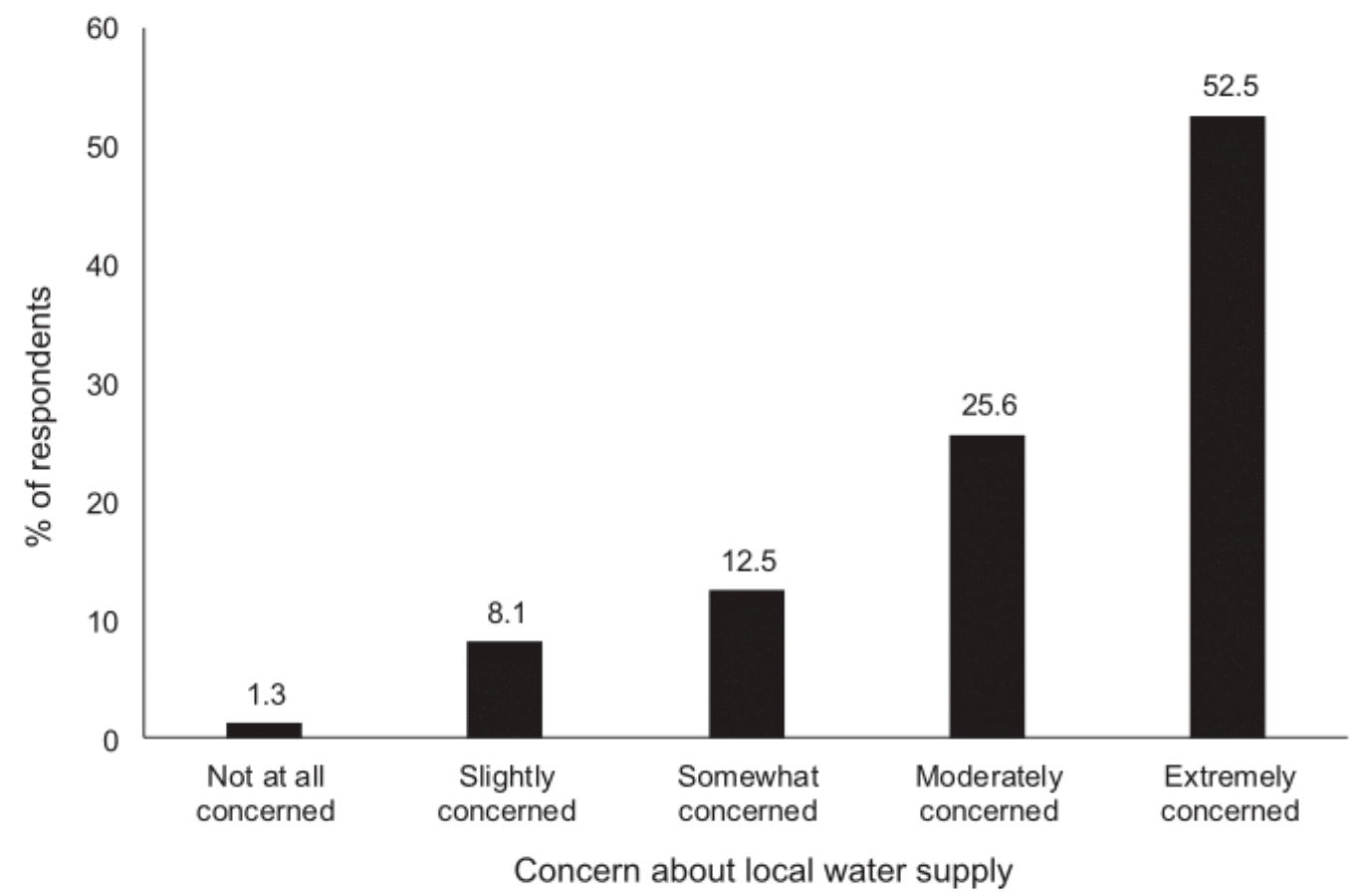

Fig. 3. Perception of local water supply in Carlsbad (\% of respondents, $N=320$ ). 


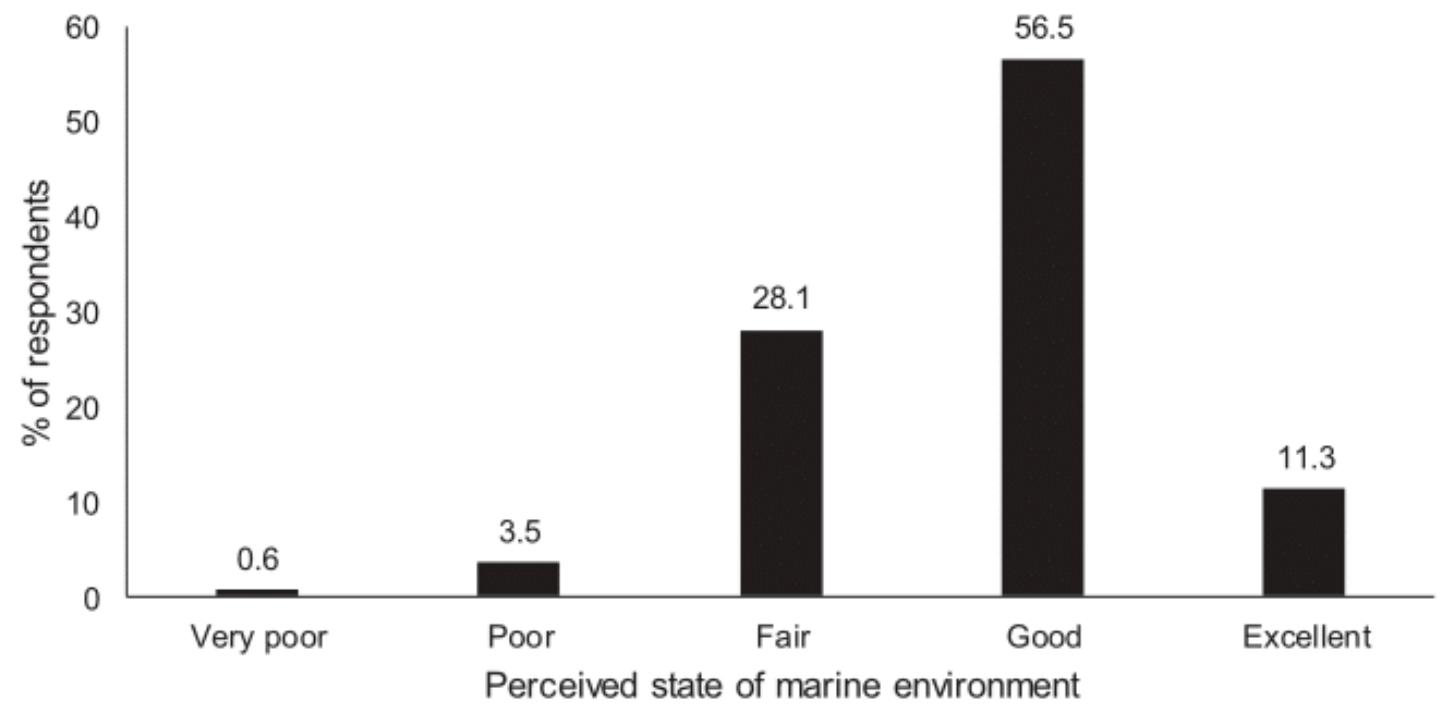

Fig. 4. Perceived state of the local marine environment (\% of respondents, $\mathrm{N}=310$ ).

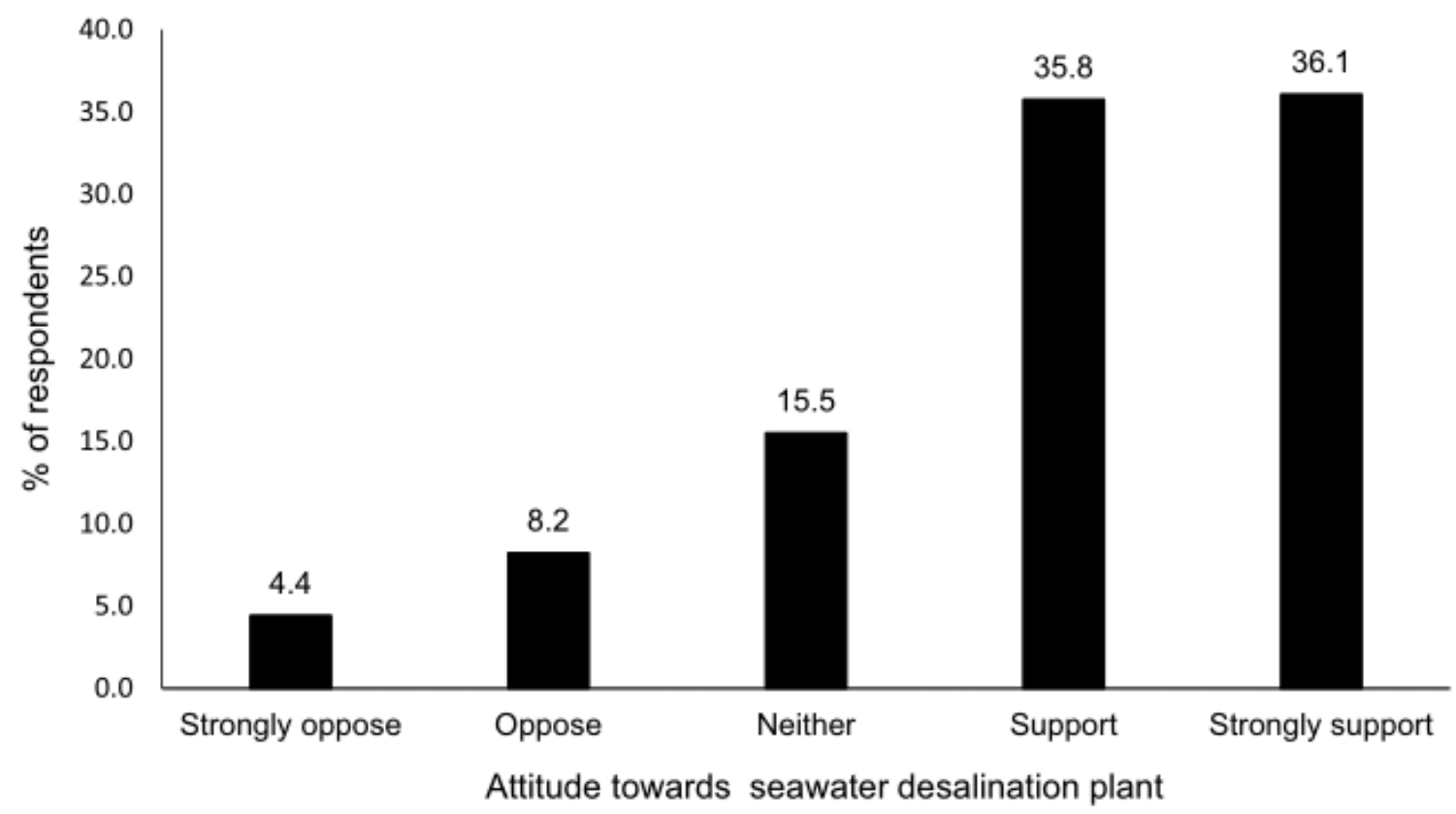

Fig. 6. Coastal residents' attitudes towards the seawater desalination plant (\% of respondents, $\mathrm{N}=330$ ).

\subsection{Perception of plant outcomes}

Residents expect negative and positive outcomes from the plant (Fig. 5). The main expected benefit was an increase in local drinking water. 
Expected negative impacts were impacts on the marine ecosystems due to water intake and brine discharge, an increase in the price for drinking water, and the amount of $\mathrm{CO} 2$ emitted from the plant, due to the high energy demand of seawater desalination.

\subsection{Local support for the plant}

The majority of respondents had clear opinions about the new facility. $71.9 \%$ respondents supported or strongly supported the new desalination facility (Fig. 6). Only $12.6 \%$ of respondents opposed the plant and $15.5 \%$ were undecided.

\subsection{Variables that shape local support}

Non-parametric correlation analysis revealed that perceptions about water resources and positive outcomes from the plant, as well as age and race were positively correlated with support for the plant (Table 4). Perceived threat to the local water supply, measured as concern for local water supply, correlated significantly and positively with support and was the variable that correlated most positively with support. An expected increase in drinking water and perceptions about the state of the local marine environment also correlated positively with support, but the correlation was weaker compared to concerns about drinking water (Fig. 7). White and older residents reported high levels of support. All other socio-demographic variables did not correlate significantly.

Perceived negative social and environmental impacts correlated significantly and negatively with support. The highest correlation coefficients were impacts on marine areas and marine activities, and disruption of coastal scenery and access. An increase in the price of water did not correlate significantly, even though residents expected an increase in the price (as seen in Fig. 5). Frequent use of marine areas also correlated significantly and negatively with support. Frequent surfers, in particular, reported less support for the plant, followed by fishermen and people who use the local beaches frequently. Place attachment correlated significantly and negatively with support indicating that not just the physical use of marine areas but also emotions and functional ties to these areas influence local support. The correlation coefficient was, however, smaller than coefficients for perceived environmental and social impacts. Place attachment therefore seems to play a role for local support, but to a smaller degree than perceptions about expected positive and negative impacts. 


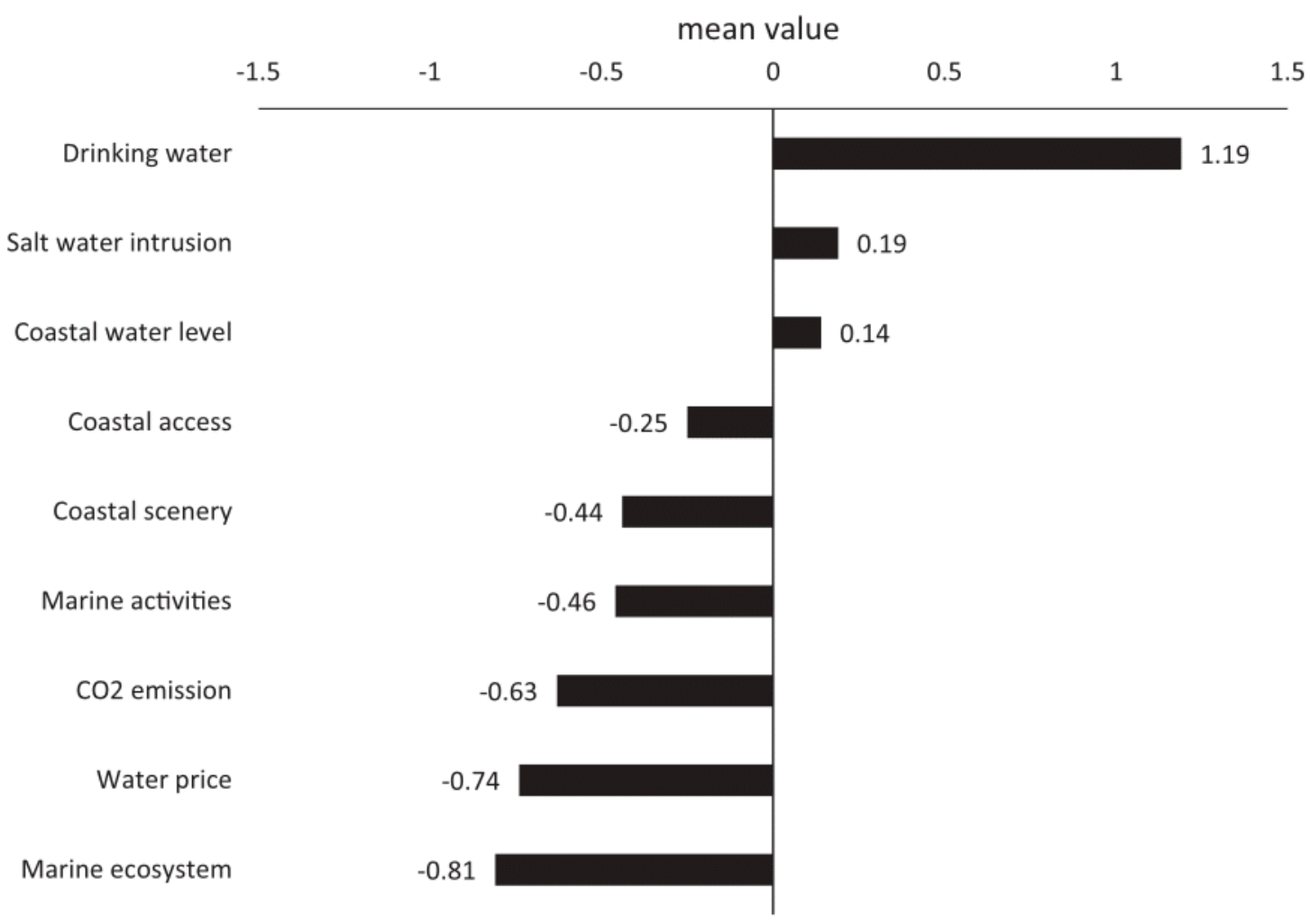

Fig. 5. Coastal residents' views on expected outcomes from the new seawater desalination plant (mean). 


\section{Table 4}

Non-parametric correlation coefficients of multiple variables with support for the seawater desalination plant (Spearman's rho).

\begin{tabular}{|c|c|c|}
\hline Variable & Correlation coefficient & $\begin{array}{l}\text { Significance } \\
\text { (2-tailed) }\end{array}$ \\
\hline \multicolumn{3}{|l|}{ Socio-demographics } \\
\hline Gender & 0.054 & 0.344 \\
\hline Education & 0.107 & 0.058 \\
\hline Age & 0.228 & 0.000 \\
\hline Race & 0.161 & 0.006 \\
\hline NGO membership & -0.103 & 0.072 \\
\hline \multicolumn{3}{|l|}{ Ocean use } \\
\hline Fishing & -0.125 & 0.028 \\
\hline Surfing & -0.191 & 0.001 \\
\hline Boating & -0.018 & 0.757 \\
\hline Beach walking & -0.124 & 0.028 \\
\hline Wildlife viewing & -0.110 & 0.054 \\
\hline \multicolumn{3}{|l|}{ Perception water resources } \\
\hline Marine environment & 0.190 & 0.001 \\
\hline Drinking water supply & 0.342 & 0.000 \\
\hline \multicolumn{3}{|l|}{ Perceptions plant outcomes } \\
\hline Increase freshwater & 0.292 & 0.000 \\
\hline Increase water level & 0.017 & 0.803 \\
\hline Less salt water intrusion & -0.650 & 0.275 \\
\hline Increase water price & -0.124 & 0.096 \\
\hline $\mathrm{CO}^{2}$ emission & -0.350 & 0.000 \\
\hline Coastal access & -0.409 & 0.000 \\
\hline Impact marine activities & -0.467 & 0.000 \\
\hline Change in coastal scenery & -0.454 & 0.000 \\
\hline Impacts ocean & -0.466 & 0.000 \\
\hline Place attachment & -0.166 & 0.003 \\
\hline Distance & 0.018 & 0.891 \\
\hline
\end{tabular}

Bold highlights significant correlations. 


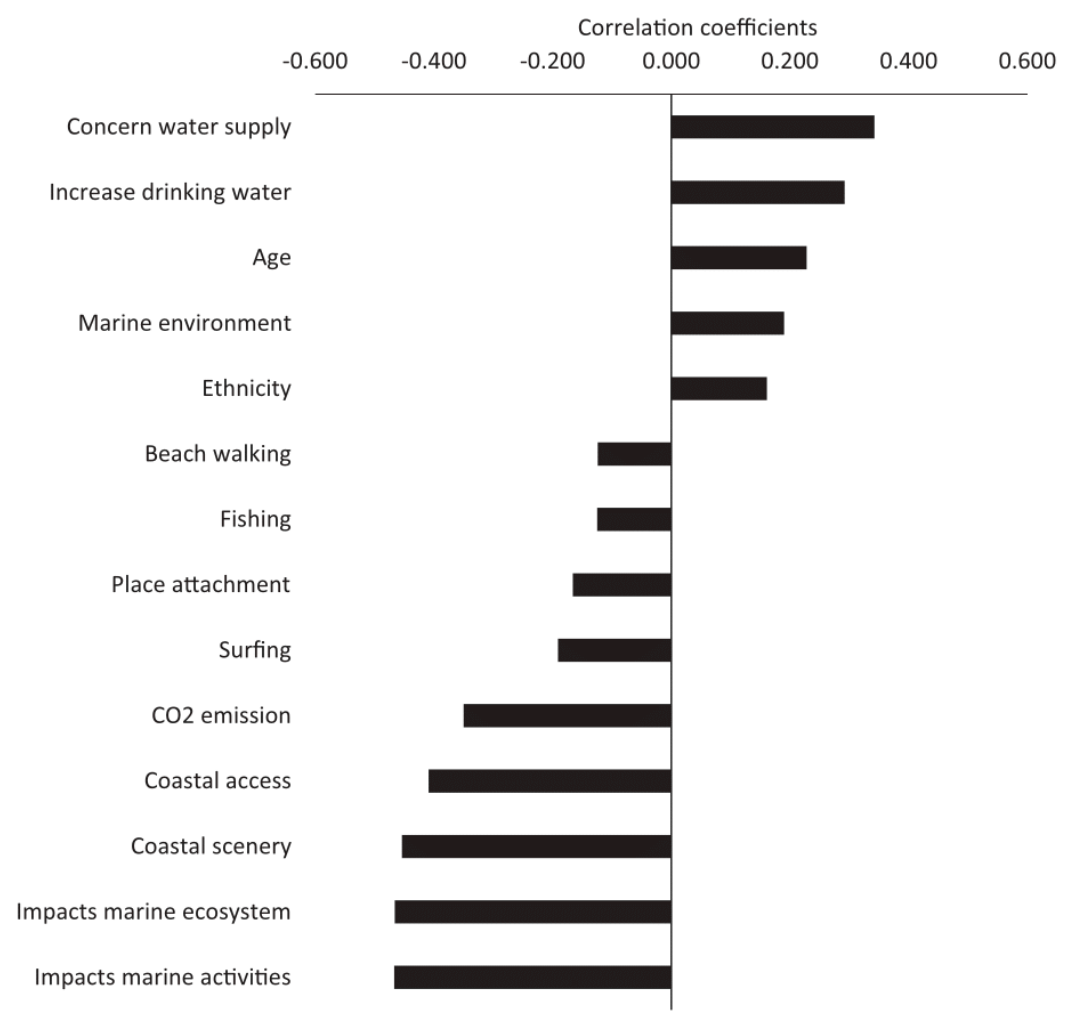

Fig. 7. Spearman correlation coefficients for significant correlations of explanatory variables with support for the desalination plant (ordered by declining support).

Concerns about the local water supply and perceived condition of the local marine environment also regressed significantly and positively with support but the regression coefficients were smaller compared to expected increase in water supply and race.

The strongest negative predictor for support were perceived negative impacts from the plant and frequent use of the local marine areas for fishing. These two variables were in fact the two strongest significant predictors in our model. Recreation and place attachment did not regress significantly, even though these variables correlated significantly and negatively with support. The correlation between place attachment and recreation (0.325), based on the correlation matrix of our model, may have contributed to the non-significant regression of these two variables (Appendix A).

\section{Discussion}

Our study provides novel insights into coastal residents' support for a local seawater desalination plant in a small coastal community in Southern California. Most residents had formed an opinion and either supported or opposed the plant with only $15.5 \%$ of respondents being undecided. More than $70 \%$ of sampled residents supported the seawater desalination plant, which is similar to findings of Gibson et al. (2015) who reported $73 \%$ and $74 \%$ support for future desalination plants in Perth, Australia, in 2007 and 2012. Perth, a large urban region, already receives about $39 \%$ of its water from two desalination plants (Water Corporation, 
2014). Carlsbad is a small coastal community and the new plant is not only the first plant in Carlsbad but also the first high capacity facility in California. The similar high support in Perth and Carlsbad suggests that the size of a community and lack of experience with desalination may have little influence on support for specific desalination projects.

One possible explanation for the strong support for desalination in Carlsbad could be that our survey was conducted in the fourth year of a prolonged drought with below average precipitation (State Water Resources Control Board, 2015). In 2015, the state of California mandated emergency conservation regulations throughout California to address severe water shortages (State Water Resources Control Board, 2015). Residents in our study who were very concerned about local water supply and expected a very positive effect from the plant on availability of drinking water reported high levels of support. Our regression model also confirmed that a perceived threat to the local water supply, measured in our study as concern, predicts support for this technology. Support may decline in periods with higher precipitation and less concern about drinking water supply. Models of longterm precipitation patterns and drinking water availability that justify the ongoing need for new plants might address this issue and maintain concern for reliability of drinking water supply and continued public support. The perceived state of the marine environment that is the plant's water source was also a significant predictor. If the health of the marine environment deteriorates (e.g. due to oil spills, harmful algal blooms), support may decline if this raises concerns about the quality of produced drinking water. Overall, these findings suggest that the environmental context of a plant plays an important role for public support.

Perceived negative impacts from the plant were the strongest predictors reducing support for seawater desalination in our study. This finding is similar to the results of Gibson et al. (2015) who also found that perceptions about outcomes predicted support for proposed desalination plants. Perceived environmental impacts in our study included impacts on the marine ecosystem due to the open-ocean intake and the discharge of brine. Use of sub-surface intake technologies and/or mitigation of impacts may increase support from community members opposing seawater desalination because of its impacts on marine ecosystems. While the plant operator has developed a mitigation plan to off-set entrainment impacts via the creation of wetlands, the plan does not consider other marine impacts.

Because the Carlsbad desalination plant is co-located with the existing Encina power plant and shares the existing intake and outfall infrastructure, the desalination plant did not require construction of additional infrastructure and associated environmental disruptions. The marine ecosystems are also already affected by water intake and outfall from the power plant. Yet, perceived impacts from the plant on the marine ecosystem were still high and significantly reduced support. Residents therefore may have been concerned about desalination-specific impacts (e.g. discharge of brine) that will add additional stress to local marine ecosystems. Future studies could investigate whether perceived impacts on marine ecosystems are different for plants that are colocated with power plants and those that are not, to identify if colocation has any effect on local perceptions and support for desalination facilities. 
Expected $\mathrm{CO} 2$ emissions from the plant, driven by the high demand of energy from nonrenewable resources, also significantly reduced support. Reduction of energy usage for the desalination plant and/or an increase in renewable energy sources could play an important role in gaining public support. The high energy demand and greenhouse gas emissions from desalination plants could further reduce support, if concerns about climate change and its impacts on marine ecosystems (e.g., ocean acidification) remain or increase. The plant operator in Carlsbad has developed a mitigation plan to offset impacts of greenhouse gas emission. It was not clear in our study if this plan had any effect on the perceived $\mathrm{CO} 2$ emission from the plant. Residents, for example, may not have been aware of the mitigation plan or might prefer to reduce rather than off-set emission (e.g., using renewable energy resources). Future research could investigate this point in more detail to provide more insights into the effect of energy use and greenhouse gas emission on support for desalination.

Expected impacts on coastal scenery and coastal access also significantly reduced support. This finding suggests that the long-term existence of the co-located power plant did not alleviate perceived impacts on coastal areas close to the plant. Even though the desalination plant is smaller than the adjacent Encina power plant, and is located further away from the beach, residents apparently still did not appreciate the additional impacts on the coastal scenery. Local residents therefore may feel protective about the coastal scenery and not welcome any further development close to the shore.

Residents who frequently use local marine areas for fishing, surfing, swimming, and beach walking were also less supportive of the new facility. The Carlsbad plant is situated at a very popular beach with a high volume of recreational use. A potential explanation for less support by surfers and swimmers may be that these activities require physical contact with ocean water in the vicinity of the plant, and people may have concerns about the quality of ocean water in areas close to the point of discharge. Monitoring water quality may help reduce conflicts with recreational users close to a desalination facility. Fishermen may worry about declining fish resources due to impingement and entrainment at the open-ocean water intake or effects of brine discharge on food webs. Engaging with marine stakeholders seems important to further understand the views of these groups on desalination and to identify and manage potential conflicts with existing marine activities.

Residents also expected an increase in the price of water but this increase did not reduce support for the plant. One explanation might be that Carlsbad is an affluent community and the benefits of a reliable water source, especially in times of droughts and plant and does not produce high levels of noise or visible point source gas emission. Residents living closer to the plant therefore may not be more affected by the plant than other residents, which may explain the absence of the NIMBY effect. In contrast, a proposed desalination plant in Santa Cruz that would have been located close to a very affluent residential neighborhood was put on hold after strong community resistance, including a number of complaints about expected impacts on quality of life and property price in residential areas close to the proposed plant (City of Santa Cruz, 2013). Hence, the siting of the Carlsbad facility may have played a role in the absence of the NIMBY concept in our study. potential mandatory water conservation measures, 
may outweigh the need to pay more for water. An increase in the price of drinking water may play a significant role for local support in less affluent communities.

Age and race were the only socio-demographic variables that predicted support with white and older residents being supportive of the plant. This finding corresponds to a study on the acceptance of using desalinated water by Dolnicar and Schäfer (2009) who also reported that white and older people were more receptive to using desalinated water. In contrast to this study, education and gender did not predict support in our study suggesting that sociodemographic variables may have larger effects on the acceptance of using desalinated water than on support for a desalination facility. Gibson et al. (2015) also reported almost no significant influence of socio-demographic variables on support for proposed desalination plants. These findings suggest that the sociodemographic profile of a community might not be a decisive factor for local support or rejection of a desalination facility.

Place attachment correlated significantly and negatively with support for the plant, indicating that strong emotional and functional ties to local marine areas shaped local views on the new facility. This finding is similar to a study by Devine-Wright and Howes (2010) who found that a perceived threat to place identity led to negative attitudes towards an off-shore wind farm. In our case, residents who attach high emotional and functional values to marine areas may perceive the new plant as a threat to those values given expected negative impacts on local marine ecosystems. Place dependence on marine areas may also explain why marine users were less supportive of the new facility, since functional ties to an area and actual use were related in our study. While place attachment and recreational use did not regress significantly in our model, both variables were correlated, which may have affected regression outcomes. At the same time, place attachment did not correlate very highly with support compared to other variables. The lack of a significant regression may also indicate that attachment to marine areas is not a good indicator of support, or lack thereof, for seawater desalination, even in small communities with strong emotional and functional ties to the ocean. More studies are needed to increase our understanding of the effects of place attachment to marine areas on support for ocean sectors such as desalination.

We found no significant effect of distance from the plant and support. Resident living closer to the plant did not support the new facility more or less than residents living further away. A limited explanatory power of proximity has also been found in multiple studies on public attitudes in other natural resource sectors (Ek 2005; Jacquet, 2012; Michaud et al., 2008) and desalination in Australia (King and Murphy, 2012). In our case, the desalination plant is located in a mainly industrial area next to the Encina power plant and separated from residential areas by the Agua Hedionda Lagoon. The desalination facility is small compared to the power

\section{Limitations}

Our study was conducted after a period of severe droughts, which could have influenced the high level of support for desalination as a climate independent water supply option. The plant in our study was also co-located with an existing power plant, which may have had an effect on 
public perceptions and support for a plant. In addition, we applied a quantitative approach to understand public support for seawater desalination. More in depth, qualitative research, similar to a study conducted by Lejano and Leong (2012) on public support for a recycled water scheme, could add more insights into our understanding of why local communities support or reject seawater desalination projects.

\section{Conclusions}

Declining reliability of imported water sources, overtaxing of coastal aquifers, and rising demands for drinking water are stimulating the development of seawater desalination in the US and in particular California. Our data provide insights into variables that shape local support of an existing recently constructed seawater desalination plant. We found that perceptions about water resources and perceived costs and benefits of desalination in terms of negative and positive impacts of the pant were significant predictors of support. Support for the plant may vary over time if environmental conditions and perceptions change. Demonstrating the need for desalination based on long-term predictions of precipitation patterns and water supply could be critical to sustain support over time. In addition, reducing or mitigating perceived impacts on marine areas and $\mathrm{CO} 2$ emission from plant operations could help to increase and sustain community support for a local facility. The findings also indicate that common criticisms of desalination, in terms of impacts on marine areas and $\mathrm{CO} 2$ emission, reduced support but economic factors did not. Additional studies are needed to identify if these expected outcomes are consistent predictors for reduced support for desalination plants or if the influence of these variables varies depending on the local context of a plant.

\section{Appendix A.}

Correlation matrix for the binary regression model

\begin{tabular}{|c|c|c|c|c|c|c|c|c|c|c|c|c|c|c|c|}
\hline & & 1 & 2 & 3 & 4 & 5 & 6 & 7 & 8 & 9 & 10 & 11 & 12 & 13 & 14 \\
\hline 1 & Constant & 1.000 & -0.350 & -0.114 & -0.421 & -0.421 & -0.041 & -0.082 & -0.129 & -0.246 & -0.379 & -0.641 & 0.028 & -0.191 & -0.096 \\
\hline 2 & Distance & -0.350 & 1.000 & 0.091 & 0.128 & 0.147 & 0.030 & -0.025 & -0.108 & 0.032 & 0.029 & 0.043 & 0.031 & -0.044 & -0.177 \\
\hline 3 & Place attachment & -0.114 & 0.091 & 1.000 & -0.082 & -0.150 & 0.102 & -0.033 & 0.017 & 0.066 & 0.040 & -0.030 & -0.027 & 0.219 & -0.326 \\
\hline 4 & Water supply & -0.421 & 0.128 & -0.082 & 1.000 & 0.023 & 0.040 & -0.017 & 0.051 & 0.016 & 0.087 & -0.055 & 0.093 & -0.155 & 0.008 \\
\hline 5 & State marine environment & -0.421 & 0.147 & -0.150 & 0.023 & 1.000 & -0.108 & -0.220 & -0.035 & -0.043 & 0.047 & 0.216 & -0.039 & -0.213 & -0.080 \\
\hline 6 & Fishing & -0.041 & 0.030 & 0.102 & 0.040 & -0.108 & 1.000 & 0.152 & 0.013 & 0.009 & 0.039 & 0.029 & -0.015 & -0.102 & -0.198 \\
\hline 7 & Negative outcomes & -0.082 & -0.025 & -0.033 & -0.017 & -0.220 & 0.152 & 1.000 & -0.108 & -0.074 & -0.077 & 0.137 & -0.180 & 0.018 & 0.055 \\
\hline 8 & Gender & -0.129 & -0.108 & 0.017 & 0.051 & -0.035 & 0.013 & -0.108 & 1.000 & 0.011 & 0.111 & -0.006 & 0.072 & 0.033 & 0.012 \\
\hline
\end{tabular}

\begin{tabular}{|c|c|c|c|c|c|c|c|c|c|c|c|c|c|c|c|}
\hline & & 1 & 2 & 3 & 4 & 5 & 6 & 7 & 8 & 9 & 10 & 11 & 12 & 13 & 14 \\
\hline 9 & Education & -0.246 & 0.032 & 0.066 & 0.016 & -0.043 & 0.009 & -0.074 & 0.011 & 1.000 & 0.128 & 0.050 & 0.023 & -0.042 & -0.089 \\
\hline 10 & Race & -0.379 & 0.029 & 0.040 & 0.087 & 0.047 & 0.039 & -0.077 & 0.111 & 0.128 & 1.000 & -0.025 & -0.104 & 0.160 & -0.179 \\
\hline 11 & Age & -0.641 & 0.043 & -0.030 & -0.055 & 0.216 & 0.029 & 0.137 & -0.006 & 0.050 & -0.025 & 1.000 & -0.085 & 0.198 & 0.269 \\
\hline 12 & NGO member & 0.028 & 0.031 & -0.027 & 0.093 & -0.039 & -0.015 & -0.180 & 0.072 & 0.023 & -0.104 & -0.085 & 1.000 & -0.022 & -0.046 \\
\hline 13 & Positive outcome & -0.191 & -0.044 & 0.219 & -0.155 & -0.213 & -0.102 & 0.018 & 0.033 & -0.042 & 0.160 & 0.198 & -0.022 & 1.000 & 0.091 \\
\hline 14 & Recreation & -0.096 & -0.177 & -0.326 & 0.008 & -0.080 & -0.198 & 0.055 & 0.012 & -0.089 & -0.179 & 0.269 & -0.046 & 0.091 & 1.000 \\
\hline
\end{tabular}

\section{Acknowledgement}

The study was funded by the National Science Foundation Coastal SEES program, award 1325649 to AP, DP, and BH. 


\section{References}

Ajzen, I., Fishbein, M., 1988. Theory of Reasoned Action-theory of Planned Behavior. University of South Florida.

Anderson, E., 2015. Drinking Water Starts Flowing from Carlsbad Desalination Plant. KPBS.

Bourne, G., 2008. California Desalination Planning Handbook. Sacramento: Center For Collaborative Policy, California State University Sacramento.

Bridgeman, J., 2004. Public perception towards water recycling in California. Water Environ. J. $18(3), 150-154$.

Côté, P., Siverns, S., Monti, S., 2005. Comparison of membrane-based solutions for water reclamation and desalination. Desalination 182, 251-257.

California Coastal Commission. (2004). Seawater Desalination and the California Coastal Act, in: Commission, C.C. (Ed.), San Francisco, CA

California Demographics. (2014). Carlsbad Demographics.

California Department of Water Resources. (2003). Desalination, in: Resources, C.D.o.W. (Ed.), Sacramento.

California Water Boards, 2014. Desalination Facility Intakes, Brine Discharges, and the Incorporation of Other Nonsubstantive Changes State of California. Environmental Protection Agency, Sacramento.

Ching, L., 2016. A lived-experience investigation of narratives: recycled drinking water. Int. J. Water Resour. Dev. 32 (4), 637-649.

City of Santa Cruz. (2013). Draft Environmental Impact Report- Public Comments. Santa Cruz, CA.

Connelly, N.A., Brown, T.L., Decker, D.J., 2003. Factors affecting response rates to natural resource-focused mail surveys: empirical evidence of declining rates over time. Soci. Nat. Resour. 16, 541-549.

Cooley, H., Heberger, M., 2013. Key Issues in Seawater Desalination in California: Energy and Greenhosue Gas Emmission. Pacific Institute Oakland, CA.

Cooley, H., Ajam, N., Heberger, M., 2013. Key Issues in Seawater Desalination in California: Marine Impacts. Pacific Institute Oakland, CA. 
Dawoud, M.A., 2005. The role of desalination in augmentation of water supply in GCC countries. Desalination 186, 187-198.

Desal Alternatives. (2013). Desals' Problems. Desal Alternatives, Santa Cruz, CA.

Devine-Wright, P., Howes, Y., 2010. Disruption to place attachment and the protection of restorative environments: a wind energy case study. J. Environ. Psychol. 30 (3), 271-280.

Devine-Wright, P., 2011. Place attachment and public acceptance of renewable energy: a tidal energy case study. J. Environ. Psychol. 31, 336-343.

Dillman, D.A., Smyth, J.D., Christian, L.M., 2014. Internet, Phone, Mail, and Mixedmode Surveys: the Tailored Design Method. John Wiley \& Sons.

Dolnicar, S., Schäfer, A.I., 2009. Desalinated versus recycled water: public perceptions and profiles of the accepters. J. Environ. Manage. 90, 888-900.

Dolnicar, S., Hurlimann, A., Nghiem, L.D., 2010. The effect of information on public acceptance-the case of water from alternative sources. J. Environ. Manage. 91, 1288-1293.

Dolnicar, S., Hurlimann, A., Grün, B., 2011. What affects public acceptance of recycled and desalinated water? Water Res. 45, 933-943.

Domènech, L., March, H., Saurí, D., 2013. Degrowth initiatives in the urban water sector? A social multi-criteria evaluation of non-conventional water alternatives in Metropolitan Barcelona. J. Cleaner Prod. 38, 44-55.

Ek, K., 2005. Public and private attitudes towards green electricity: the case of Swedish wind power. Energy Policy 33, 1677-1689.

Elimelech, M., Phillip, W.A., 2011. The future of seawater desalination: energy, technology, and the environment. Science 333, 712-717.

Friedler, E., Lahav, O., Jizhaki, H., Lahav, T., 2006. Study of urban population attitudes towards various wastewater reuse options: Israel as a case study. J. Environ. Manage. 81, 360-370.

Fuentes-Bargues, J.L., 2014. Analysis of the process of environmental impact assessment for seawater desalination plants in Spain. Desalination 347, 166- 174.

Gee, K., Burkhard, B., 2010. Cultural ecosystem services in the context of offshore wind farming: a case study from the west coast of Schleswig-Holstein. Ecol. Complexity 7, 349-358.

Gibson, F.L., Tapsuwan, S., Walker, I., Randrema, E., 2015. Drivers of an urban community's acceptance of a large desalination scheme for drinking water. J. Hydrol. 528, 38-44. 
Gray, D.L., Canessa, R.R., Rollins, R.B., Dearden, P., Keller, C.P., 2010. Understanding recreational boater attitudes to zoning in a proposed marine protected area. Coastal Manage. 38, 575-597.

Halpern, B.S., Walbridge, S., Selkoe, K.A., Kappel, C.V., Micheli, F., D'Agrosa, C., Bruno, J.F., Casey, K.S., Ebert, C., Fox, H.E., 2008. A global map of human impact on marine ecosystems. Science 319, 948-952.

Hartley, T.W., 2006. Public perception and participation in water reuse. Desalination 187 (1), $115-126$.

Heberger, M., Cooley, H., Herrera, P., Gleick, P., Morre, E., 2009. The Impacts of Sea-Level Rise on the California Coast. Pacific Institute, Oakland, CA.

Hinkebein, T.E., Price, M.K., 2005. Progress with the desalination and water purification technologies US roadmap. Desalination 182, 19-28.

Hurlimann, A., Dolnicar, S., 2010. When public opposition defeats alternative water projectsthe case of Toowoomba Australia. Water Res. 44, 287-297. International Desalination Association. (2014). Desalination by Numbers.

Jacquet, J.B., 2012. Landowner attitudes toward natural gas and wind farm development in northern Pennsylvania. Energy Policy 50, 677-688.

Johansson, M., Laike, T., 2007. Intention to respond to local wind turbines: the role of attitudes and visual perception. Wind Energy 10, 435-451.

Kahn, R.D., 2000. Siting struggles: the unique challenge of permitting renewable energy power plants. Electr. J. 13, 21-33.

King, T.J., Murphy, K., 2012. Procedural Justice as a Component of the Not In My Backyard (nimby) Syndrome: Understanding Opposition to the Building of a Desalination Plant in Victoria Australia. Alfred Deakin Research Institute.

King, T.J., Ooi, D., Cary, J., Fisher, A., Schibeci, R., Murphy, K., O’Toole, K., Mearns, M., Donaldson, J.A., 2012. Public Perceptions Of, and Responses To, Desalination in Australia, Alfred Deakin Research Institute Working Paper Series. Deakin University.

Lattemann, S., Höpner, T., 2008. Environmental impact and impact assessment of seawater desalination. Desalination 220, 1-15.

Lejano, R.P., Leong, C., 2012. A hermeneutic approach to explaining and understanding public controversies. J. Public Administration Res. Theory 22 (4), 793-814. 
Liu, T.-K., Sheu, H.-Y., Tseng, C.-N., 2013. Environmental impact assessment of seawater desalination plant under the framework of integrated coastal management. Desalination 326, 10-18.

Mainali, B., Ngo, H., Guo, W., Pham, T., Wang, X., Johnston, A., 2011. SWOT analysis to assist identification of the critical factors for the successful implementation of water reuse schemes. Desalin. Water Treat. 32, 297-306.

Mankad, A., Tapsuwan, S., 2011. Review of socio-economic drivers of community acceptance and adoption of decentralised water systems. J. Environ. Manage. 92 (3), 380-391.

Manning, R., 2011. Studies in Outdoor Recreation: Search and Research for Satisfaction. Oregon State University Press, Corvallis, Oregon, USA.

Marks, J.S., 2004. Advancing Community Acceptance of Reclaimed Water. Australian Water and Wastewater Association.

Martin, C.A. (2015). Landscape water use in Phoenix, Arizona. Desert Plants.

Michaud, K., Carlisle, J.E., Smith, E.R.A.N., 2008. Nimbyism vs: environmentalism in attitudes toward energy development. Environ. Politics 17, 20-39.

Miller, S., Shemer, H., Semiat, R., 2015. Energy and environmental issues in desalination. Desalination 366, 2-8.

Mirchi, A., Madani, K., Roos, M., Watkins, D., 2013. Climate change impacts on california's water resources. In: Schwabe, K., Albiac, J., Connor, J.D., Hassan, R.M., Meza González, L. (Eds.), Drought in Arid and Semi-Arid Regions. Springer, Netherlands, pp. 301-319.

Monterey Bay National Marine Sanctuary, National Marine Fisheries Service. (2010). Guidelines for Desalination Plants in the Monterey Bay National Marine Sanctuary.

Natural Resources Defense Council, N. (2014). Proceed with Caution: California' Drought and Seawater Desalination, NRDC Issue Brief May 2014.

Natural Resources Defense Council, New York.

Oki, T., Kanae, S., 2006. Global hydrological cycles and world water resources. Science 313, 1068-1072.

Pasko, J., 2013. A Change of Plans. Good Times. 
Peel, J., Choy, J., 2014. Water governance and climate change. Drought in California as a Lens on Our Climate Future. Stanford Woods Institute for the Environment, Stanford.

Perry, E.E., Needham, M.D., Cramer, L.A., Rosenberger, R.S., 2014. Coastal resident knowledge of new marine reserves in Oregon: the impact of proximity and attachment. Ocean Coastal Manage. 95, 107-116.

Pidgeon, N.F., Beattie, J., 1998. The Psychology of Risk and Uncertainty. Blackwell Science, London.

Pierce, J. (2013). A History of Santa Cruz's Desal Fight.

Poseidon Water. (2008). Poseidon Resources Marine Life Mitigation Plan Poseidon Water, Carlsbad.

Poseidon Water. (2016). Carlsbad Desalination Plant. Online available at http://carlsbaddesal.com/faqs (accessed 08.01.2016).

Ressurreição, A., Simas, A., Santos, R.S., Porteiro, F., 2012. Resident and expert opinions on marine related issues: implications for the ecosystem approach. Ocean Coastal Manage. 69, 243-254.

Roberts, D.A., Johnston, E.L., Knott, N.A., 2010. Impacts of desalination plant discharges on the marine environment: a critical review of published studies. Water Res. 44, 5117-5128.

San Diego County Water Authority. (2012). Seawater Desalination.

San Diego County Water Authority, 2014. Seawater Desalination: The Carlsbad Desalination Project. San Diego County Water Authority, San Diego.

Sanchez-Lizaso, J.L., Romero, J., Ruiz, J., Gacia, E., Buceta, J.L., Invers, O., Torquemada, Y.F., Mas, J., Ruiz-Mateo, A., Manzanera, M., 2008. Salinity tolerance of the Mediterranean seagrass Posidonia oceanica: recommendations to minimize the impact of brine discharges from desalination plants. Desalination 221, 602-607.

Schiffler, M., 2004. Perspectives and challenges for desalination in the 21st century. Desalination 165, 1-9.

Seller, J., 2008. Desalination policy in a multilevel regulatory state. In: Escuder, C., Bert, G. (Eds.), Desalaction de agua con Energias Renovables. National Autonomous University of Mexico Press, Mexico City, pp. 173-188. 
Sellers, J., 2008. Desalination policy in a multilevel regulatory state. In: Escuder, C.N., Bert, G.H.L. (Eds.), Desalaction de agua con Energias Renovables. National Autonomous University of Mexico Press, Mexico City, pp. 173-188.

State Water Resources Control Board, 2014. Amendment to the water quality control plan for ocean waters of California. In: Agency, C.E.P. (Ed.), Draft Staff Report Including the Draft Substitute Environmental Documentation. State Water Resources Control Board, Sacramento.

State Water Resources Control Board. (2015). Emergency Conservation Regulations. Implementing 25\% Conservation Statewide.

State of California Public Utilities Commission, 2015. Am Monterey Peninsula Water Supply Project. California Public Utilities Commission.

Stedman, R.C., 2002. Toward a social psychology of place predicting behavior from place-based cognitions, attitude, and identity. Environ. Behav. 34 (5), 561-581.

Swofford, J., Slattery, M., 2010. Public attitudes of wind energy in Texas: local communities in close proximity to wind farms and their effect on decisionmaking. Energy Policy 38, 2508-2519.

Theodori, G.L., Wynveen, B.J., Fox, W.E., Burnett, D.B., 2009. Public perception of desalinated water from oil and gas field operations: data from Texas. Soc. Nat. Resour. 22, 674-685.

Tortajada, C., Joshi, Y.K., 2013. Water demand management in Singapore: involving the public. Water Resour. Manage. 27 (8), 2729-2746.

United States Census Bureau. (2014). Carlsbad, California.

Vaske, J., 2008. Survey Research and Analysis: Applications in Parks, Recreation, and Human Dimensions. Venture Publishing, State College, PA.

Vorkinn, M., Riese, H., 2001. Environmental concern in a local context: the significance of place attachment. Environ. Behav. 33, 249-263.

Water Corporation, 2014. Annual Report. Online available at https://www.watercorporation.com.au/-/media/files/about us/ourperformance/annualreport/annual-report-2014/water-corporation-annual report2014.pdf (accessed 08.27.16.).

Williams, D.R., Vaske, J.J., 2003. The measurement of place attachment: validity and generalizability of a psychometric approach. For. Sci. 49, 830-840.

Wolsink, M., 1994. Entanglement of interests and motives: assumptions behind the NIMBYtheory on facility siting. Urban Stud. 31, 851-866. 
Wolsink, M., 2000. Wind power and the NIMBY-myth: institutional capacity and the limited significance of public support. Renewable Energy 21, 49-64.

World Water Assessment Programme. (2009). The United Nations World Water Development Report 3: Water in a Changing World. UNESCO Paris.

Wynveen, C.J., Kyle, G.T., Absher, J.D., Theodori, G.L., 2011. The meanings associated with varying degrees of attachment to a natural landscape. J. Leisure Res. 43, 290. 